\title{
"An Attempt to Tip the Scales": Music and Embodied Capital in an English Secondary School
}

\section{Dominic Pollard}

\section{Patrick Alexander}

\begin{abstract}
:
This paper explores class, capital, and aspiration to social mobility in an ethnographic study of an English secondary school. In particular, the paper considers the school's musical instrument programme as a site for inculcating forms of capital, under the auspices of developing skills for upward social mobility. Bringing together Bourdieu's $(1984,1986)$ conceptions of schooling with theories of materiality (Latour 1987) and situated learning (Lave \& Wenger, 1991), we contend that this school succeeds in cultivating new forms of embodied capital among students through the development of communities of musical practice (Lave \& Wenger, 1991; Kenny 2016). However, a tension remains between emancipatory aims of the programme and the sanctioning and championing of certain forms of dominant cultural practice. The learning environment of the instrument programme highlights the complex and conflicted impact that schooling can have on the development of cultural capital and on reproducing disadvantage and difference.
\end{abstract}

Keywords: music; materiality; capital; Bourdieu; social mobility; communities of practice; schooling 


\section{Introduction}

The following ethnographic case study of an English secondary school explores how students develop, value, and contest forms of embodied and cultural capital (Bourdieu 1984, 1986) in the context of its musical instrument programme. The school (known here as Regents Park Academy, or Regents Park) is located in an underprivileged, ethnically diverse area of North London. Its instrument programme provides students with the opportunity of learning a classical instrument (specifically violin, viola or cello) for a minimum of three years for free, during which time students are allowed to retain possession of their instrument. The students' low socioeconomic status and, for some, religious upbringing, mean few have received any prior instrument tuition. That formally taught musical instrument playing represents a form of cultural capital is not a novel observation (Bourdieu 1984, 10), but its acquisition is normally associated with conditions of socioeconomic privilege (Goodman et al. 2010). In the context of this research, musical instrument learning in the classical tradition is presented as a means to social mobility exactly because of its association with socioeconomic privilege and 'high' culture, often to the exclusion of other forms of musical and cultural expression deemed less 'valuable' as forms of capital (for example, Hip Hop music). Over the course of the programme, this confluence of ideas about music, culture, and potential for social mobility become embodied by the students. On occasion, these ideas are also contested through embodiment. Drawing on theories of materiality and communities of practice (Lave \& Wenger, 1991), we explore the tension inherent in this 'attempt to tip the scales', as one teacher at Regents Park described it - that is, a tension between the emancipatory aims of the instrument programme and the ways in which it nevertheless reinforces a hierarchy of forms of cultural expression, privileging certain kinds of dominant cultural practice within an unproblematic framing of social mobility. 
We begin by setting out the theoretical parameters of the study, indicating the value of combining three distinct but interconnected theoretical fields to this research. We then present the research context and methods before exploring the findings through a series of ethnographic vignettes. In turn, these vignettes document: a) the framing of aspiration and social mobility in the environment of the school, focusing on bodily comportment and noise (or a lack thereof); b) contested notions of embodied and cultural capital as they are developed in the musical instrument programme; and c) the process of nurturing forms of capital, as articulated in the community of practice that is the school orchestra. We conclude by suggesting that even the most laudable attempts 'to tip the scales' of social justice in schools can become ensnared in neoliberal discourse about social mobility and aspiration, in ways that may ultimately serve to stabilise the very markers of difference that they set out to topple.

\section{Theoretical Background}

This study is framed by theoretical considerations of Bourdieu's concepts of embodied and cultural capital in relation to schooling, complicated in response to theories of situated learning (Lave \& Wenger 1991) and anthropological notions of materiality. Here we frame materiality as the relationships between persons and 'things', and in this case specifically the relationship between teachers, students, and their musical instruments (Latour 2005). These persons and things are interconnected and mutually implicated in the formation and reproduction of forms of capital as defined by Bourdieu ( 1977a; 1984), particularly in relation to education (Bourdieu \& Passeron 1977; Bourdieu 1996) and taste (Bourdieu 1984). Embodied cultural capital, that form of cultural capital relating to long-lasting dispositions of the mind and body, such as instrument playing (Bourdieu 1986, 85), is to Bourdieu 'the best hidden form of hereditary transmission of capital' (Bourdieu 1986, 86). The un- or misrecognised nature of embodied capital as a natural disposition rather than the result of practice means that inequalities of power 
in society are systemically mistaken for more innocent differences; aptitudes for engaging in legitimate cultural practice are misconstrued as functions of personal ability or taste (Bourdieu $1984,21)$

The school, argues Bourdieu, validates the cultural capital already disproportionally held by those in positions of social and economic advantage (Bourdieu \& Passeron 1977, 72). As schools endorse positions and perspectives within the fields of knowledge and taste based on the preferences of those in arbitrary possession of social power (Moore 2004), the children of these power-holders are inherently more receptive to the forms of practice fostered by the school. Other children are conversely predisposed to underachieve. While this does not fully articulate the complexity of how processes of social and cultural production and reproduction take place in schools (Moore 2004, 453; Bourdieu and Passeron 1977, 83; Goldthorpe 2007, 4-5), Bourdieu provides a powerful point of departure for framing how, at the subtle level of embodied capital, ideas about culture and its value are instilled through everyday movements and everyday sounds in the classroom. Importantly, Bourdieu also notes the illusory nature of these forms of capital as a direct means of changing one's position in society - whether explicitly-held beliefs about culture and taste or implicit and deeply held as aspects of habitus and comportment. Bourdieu's concept of misrecognition is a useful way of articulating the uncomfortable gap between what social, cultural, or economic advantages an activity or disposition is assumed to provide for those practicing it within a given field, and the potentially less benevolent outcomes that underpin the practice in terms of reinforcing asymmetries of power. This is an aspect of Bourdieu's argument largely missing from the mainstream political co-opting of terms like 'cultural capital' as an unproblematic language for calculating the cumulative ingredients required for social mobility. Zipin (2015), drawing on Bourdieu, argues instead that 'doxic' and 'habituated' logics of aspiration serve to reinforce through schooling a particular vision of social mobility linked to the development of certain forms of capital 
rehearsed through socialisation into neoliberal values and the values of social elites (in this case, learning to play a musical instrument). In ultimately failing to produce the forms of emancipation, equity, success, or self-efficacy normally enveloped and implicit in what is understood by the term 'social mobility', these logics of aspiration are resonant of Berlant's notion of 'cruel optimism' (2011) - that is, a set of seemingly unquestionable, benign goals towards which we strive but which are simultaneously those things most likely to inhibit our progression towards a sense of meaningful existence, self-worth, or self-efficacy. Zipin's third logic of aspiration - an emergent, radical, creative logic of aspiration - provides a hopeful alternative through which doxic and habituated ways of viewing one's practice can be challenged and augmented.

\section{Situated Learning}

Theories of situated learning are useful in this sense because they offer a framework for understanding how doxic and habituated logics of aspiration are articulated through practice, in the pursuit of forms of capital, and sometimes in the formation of an emergent logic of aspiration that frames educational practice critically. With this in mind, Lave and Wenger's (1991) concept of Legitimate Peripheral Participation (LPP) provides the framework for the discussion of the instrument programme in this article. LPP centres on 'communit[ies] of practice' (Lave \& Wenger 1991, 29-31; Lave 1982), groups engaged in common forms of activity wherein, despite the absence of 'formal' teaching, there is a continual cycle between novices and masters facilitated by gradual inclusion into more complex forms of situated practice. LPP offers a powerful heuristic for transcending boundaries of 'formal' and 'informal' teaching and learning. Furthermore, it is, at heart, a theory of social production and reproduction, and one which provides a model for better illustrating how the development of cultural capital occurs in practice. The idea of situated learning can seem alien to the context formal schooling, where the abilities or aptitudes being taught are often divorced from the 
material and social context of their eventual use (Green 2005, 27-30). Lave and McDermott $(2002,21)$, in their re-reading of Marx's Estranged Labour, suggest that institutional education prioritises forms of knowledge with a 'distributional capacity', enabling discrimination between individuals, supposedly on the basis of 'knowledge', but in reality through predefined social categories such as class, race, gender and age. This process alienates individuals from the real value of situated learning. We suggest that the instrument programme at Regent's Academy may provide an example of how learning that is situated, contextual, and emergent from groups of organic practice (Lave \& McDermott 2002, 24) can be facilitated in institutional, formal educational settings, even when taking place concurrent to practices that may serve to alienate individuals from situated learning.

\section{Materiality}

The discussion of the situated nature of learning in the music programme draws too on anthropological theories of materiality, which help conceptualise the relationships between people and the 'things' with which they interact. Such approaches owe much to the work of Bruno Latour and Actor-Network Theory (ANT) (e.g. Latour 1987; Latour 2005). ANT views humans and their physical surroundings as not qualitatively different, with agency of social action located in 'actor-networks', those relationships or bonds between the human and material 'actants' in a system (Miller 2005, 11-12). In this scheme, 'the prime mover of an action becomes a new, distributed, and nested set of practices [mediated by] all the actants mobilized in the series' (Latour 1999, 181). Objects are saturated with the intentions of their makers and users, and come to influence our behavioural responses to them. A musical instrument, for instance, may prompt certain physical postures, gestures or movements in its player (Miller 1987; 2005). Material approaches sit well with the theories of Bourdieu, for whom distributions of objects in the physical world are a central mechanism of social reproduction (e.g. Bourdieu 1970; 1977b), and also complement those of situated learning 
because they emphasise the material conditions - the tools, instruments, and settings - in which learning is situated (Collins and Duguid 1989, 13).

\section{Research Context: Regents Park Academy}

We have now laid out the main theoretical strands which underpin the following exploration of instrument learning at Regent's Academy. Bourdieu's concept of cultural capital forms the basis of the discussion of the orchestra programme. Theories of situated learning and materiality are employed to illustrate a mechanism by which cultural capital may be conferred. However, this bringing together of different theoretical positions is shown to expose a tension between the school's ambitions to encourage social mobility and student self-efficacy, and the dominant forms of cultural practice by which these are approached. This, finally, leads to a discussion of the aims and nature of 'social mobility' as highlighted by this example of schooling.

\section{Methods}

The fieldwork for this ethnographic study was carried out over a four-week period in June and July of 2014. The main focus was the music lessons and orchestra programme of the school, and specifically the first three year groups, that is, Years 7, 8 and 9, for whom instrument lessons were compulsory. Lessons, tutor periods, break times and orchestra rehearsals were all observed, including both music and non-music lessons so the music department could be situated within the broader operations of the school. Augmenting these observations were 28 semi-structured interviews, seven with groups of five students, three with music teachers, and a further 19 with individual students. The interviews, which included a cross-section of ages and genders, were divided into a number of different topics, including the nature of instrument lessons, the types of music the children engaged with most in and out of school, the role of instruments in the learning process, and the importance of music to the school. A survey 
covering a similar range of topics was distributed among the three year-groups under consideration and yielded 85 responses. All names are pseudonyms.

\section{Regent's Park Academy: History and Context}

Regent's Academy is a non-selective, non-denominational, mixed-gender, combined primary and secondary school, first opened in 2007. It is located in a deprived ward in a London borough. The borough council profile on this ward places it below the borough average in terms of income, employment, house price, and home ownership. Less than one quarter $(22 \%)$ of the ward population is White British, $14 \%$ are of Arabic origin, and Bangladeshi and Black African residents account for 11 and $9 \%$ respectively. While over $50 \%$ of borough inhabitants on average have an NVQ level 4-5 or qualifications above, just $26 \%$ of ward residents have the same, and $28 \%$ lack any qualifications at all.

The school is almost entirely composed of children from this ward. According to the Department for Education, of the 781 pupils in the primary and secondary school, $67.4 \%$ have English not as a first language. Furthermore, $46 \%$ are currently eligible for free school meals, and $12 \%$ have a statement of special educational needs, placing the school in the highest quintile nationally on both measures. In short, Regents Park caters for a population underprivileged in terms of education, employment, housing and health. Children of Arabic backgrounds, and of Muslim faith, represent a majority, with smaller numbers of children of White British, East Asian and Black African descent.

\section{Ethos at Regents Park: '100\% Everyday!'}

Upon entering Regent's Academy, off a quiet street set back from one of London's major thoroughfares, visitors are greeted with a large banner which reads, "Climbing the Mountain to University". At the top of the staircase to the left a similar banner proclaims " $100 \%$ Everyday!", while "Whatever it Takes" is emblazoned along the wall of an upstairs corridor. The doors of form rooms bear the names of universities - Bournemouth, Manchester, Reading. 
Furthermore, each year group is named by the year they will finish $6^{\text {th }}$ Form. The school is unapologetic about the intentions behind these names and displays: they encapsulate the aim of providing educational opportunities otherwise lacking for the local community, whilst also reminding students of the expectations for social mobility placed on them.

Students come to embody different forms of capital in the school articulated in relation to sound, which in turn is used symbolically to articulate notions of control, order, and 'appropriate' comportment. The entrance hall is the crossroads through which all students pass. It is, however, a very quiet place. Students moving between lessons do so in silent lines, and only in the freedom of the playground do noise levels pick up. Lines on the corridor floors divide the traffic of students who move in orderly silence. The classrooms are organised in a uniform manner, and while displays vary, all feature identical posters outlining identical rules of behaviour and identical assessment criteria. All feature the motivational messages which appear in the entrance hall and corridors. There are several behavioural regulations, particularly in relation to sound. Firstly, clapping is used to mark transitions between vocal, creative periods and silent, focussed ones. A call and response rhythm, wryly described by one teacher as 'everyone's favourite rhythm', is used; the teacher claps the phrase dum-dum-di-dum-dum, and the children respond with a resounding $D U M-D U M$. The beginning of lessons and assemblies, the conclusion of tuning up in orchestra rehearsal, and the end of small timed activities in class are all marked by this rhythm. It permeates the school and is a universally recognised indication that conversation must end and attention must be paid. Similarly, a count down from three by a teacher, followed by two synchronous claps by the students, serves as the alternative to a round of applause. The same is true of finger clicks, which are used by students and teachers to indicate they like what they are hearing, or want to express congratulations for another. Clicking provides an audible but minimally disruptive way of expressing appreciation and, like the clapping, is consistently applied across the school. Of note is the bodily focus of so many 
of these regulations, and the frequent tying of them to aspirations of future success. Teachers enforce a system called TRACKing, which outlines not only the importance of, but the appropriate postures and behaviours which accompany good listening, and the rewards this will bring in job and university interviews are repeatedly emphasised by teachers. Belief in the causal relationship between refined bodily comportment and social success is deeply felt at the school; indeed, during the research, it was warned that the efficacy of these regulations should not be discussed with the students, lest their faith in them be undermined.

\section{Instrument Learning and Embodied Capital}

This linking of bodily aptitudes and social aspiration achieves its clearest expression in the school's orchestra programme. Far from being subconscious or epiphenomenal, we contend that the cultural capital of instrument playing is recognised as such by the school, and that the instrument programme is an explicit attempt to impart such a form of capital. The programme began in 2011 and, by the time of research, was well established. In Year 7 every pupil is given a string instrument - a violin, viola or cello - which is theirs to keep, take home, play and learn for a minimum of three years. If they choose to take GCSE Music or to join the Upper School Orchestra they are allowed to keep their instrument into Years 10 and 11. Most importantly, the entire project is free. Pupils have music lessons every day, and these take three forms. In 'small groups', a form is split into groups of four or five and taken through a focussed rehearsal by a teacher. The close, technical focus of 'small groups' contrasts with larger, whole-form rehearsals wherein a class practices together, with attention to relating the work of each section to the others, such as through refinement of timing, dynamics and tuning. These are the only two lesson types for Year 7 students. From the end of Year 8 onwards, however, there are orchestra rehearsals, with the whole year-group. In these, the sectional focus of the form-group 
rehearsals is expanded, as students are encouraged to consider their playing in the context of the full orchestra.

\section{Situating Musical Practice at Regent's Academy}

Most students had no formal musical exposure before attending Regents Park. The survey revealed at least $85 \%$ had never been taught an instrument, and most who had revealed this was in primary school, and only for very short periods. The situation was illustrated by the Head of Music (Miss Peters), who explained:

We did a survey of what the kids could already play and ... so we got some trumpets out of that, some flutes ... and so we bought trumpets and we bought flutes. Turns out, we give them their trumpet, and they literally don't know how to play it 'cause they've had about one term's lesson on it.

The Assistant Head of Music, Mr Samson, replied more bluntly to the question of pupils' prior formal musical education: 'it's pretty much zero'. Miss Peters explained that 'most of our families don't have high income ... or even the space ... does everyone want to listen to little Tommy playing the violin in what is really quite a small flat?' Bourdieu notes that the social value of 'noble instruments' stems largely from 'the rarity of the conditions for acquiring the corresponding dispositions' to play them (1984, p.10), and 'the length of time for which a given individual can prolong his acquisition process depends on the length of time for which his family can provide him with the free time' (1986, p.285), something implicitly limited by both economic means and living space.

In addition, as Miss Peters explained, 'it's not a secret that Muslim families don't prioritise music. Culturally it's not done.' The relationship between Islam and music is long and complex. As Halstead $(1994,153)$ explains, 'for some Muslims...music is a waste of time, a diversion from more important things in life. For others, it is a dangerous enticement to believers, a product of the devil. For others again, it is a harmless pastime.' The latter sentiment was not 
borne out in the research, but a number of students expressed a relatively noncommittal, or utilitarian approach to music, such as Uzma in Year 8, who stated, '... music's not really that big a part of me, because for me the big part of me is my religion, my family and, like, how I live my life, and the music just comes because I listen to it sometimes'.

The school, meanwhile, emphasises the social advantages that come with a rich education in music. Mr Samson commented on its ability to 'expand ... cultural horizons. So for example if The Proms are happening in London for kids of any background to feel that that's something they could go to', while Miss Peters commented that 'I think it's about soft skills ... transferrable skills'. More specifically, the Music Department at Regent's Academy conceives of the instrument programme as a redress to the social disadvantages experienced by its students. Miss Peters stated, 'I think, because we know that most of our kids are coming from homes where they're not being provided with musical opportunities by their families, we are surrogate for that'. She further explained participation in the orchestra is 'something that will look impressive on a CV or a uni[versity] application', a sentiment that has clearly filtered down to the students:

Amir: I think [music is] important 'cause it like widens your understanding of other subjects so they say that if you play an instrument it helps you learn like maths and that. Aleah: I heard that, I remember them saying something, that the statistics of people who get into university and like learn instruments or something, or like specialised in something different are really high.

Though not referred to as 'cultural capital', the recognition that music provides opportunities for valued forms of cultural participation in later life - something essentially synonymous with the term - is clearly in evidence. However, Mr Samson's conviction that his students may come to see The Proms as 'something they could go to, not just some posh person's thing' reveals a deep tension within the programme. He is clearly aware people from demographics such as 
those of his pupils are generally not those who engage in 'posh' forms of cultural participation, like The Proms. The intention to redress this situation is admirable, but implicit to it is the assumption that the Proms nonetheless represent a rightly-valued form of cultural participation. The unspoken implication is that social mobility and self-efficacy for these children will come from immersion in such legitimate cultural practice, rather than, for instance, the validation of practices otherwise derived from their upbringing. At Regents Park, social mobility is conceptualised mostly as an ideal attainable through the accrual of certain capacities and bodies of knowledge. The derivation, content, or social implications of these bodily and cognitive capabilities, and, specifically, how these vary in relation to the social field of the individual, are seldom problematised.

\section{Conflicting Tastes}

Though some pupils suggested that they engage little, if at all, with music because of their Muslim faith, $89 \%$ responded that they listen to it for pleasure, relaxation or social reasons when asked the survey question 'Where does music feature most prominently in your life outside of school?'. In interviews, when questioned about their musical tastes, students mostly brought up rap, hip-hop, or particular artists of those styles, such as Eminem, who was mentioned multiple times. Aisha, a Year 9 girl, discussed how her music compared to that she felt was represented by the school:

Aisha: People like music, like there are people that really like music and when they think of music, like orchestra and string instruments aren't the first things that come to mind. They have like rap and beat and...

Interviewer: So on that point then, the ways in which you're exposed to music in school, how do they differ to the kind of music you would listen to outside of school? 
Aisha: Um...because these are, like, they're, like, string instruments but some people, they'd have different things that they listen to. For example, I listen to rap and I listen to, like, normal songs that don't include these kind of instruments...

Aisha's comments, in particular her reference to 'normal songs', highlights a divide discussed by Ericsson (2002; cited in Folkestad 2006), between situated and institutional contexts of music learning and consumption. Ericsson distinguishes music, the world of social, personal, and pleasurable engagement, mostly outside of school, from Music, the discipline as taught in schools. Such a divide was recognised by teachers and students alike. Salma, a Year 8 girl described how, 'at home when we listen to music, we don't understand it how we understand it in school. They make us, like, look into it even more but when we're at home we just listen to it.' Miss Peters expressed a similar sentiment:

I think that they see it [Music the subject] as a completely different thing to what they listen to at home. The music they listen to is their music, there's a real like ... I think real personal attachment that kids all have to music that they're listening to ... I don't think they necessarily think of it in a musical sense.

Miss Peters' use of the word 'musical', like Aisha's choice of 'normal', illuminates a set of assumptions which underpins the disparity between the two musical worlds laid out by Ericsson (2002), not to mention the divisions between 'high' and 'low' culture as explored by Bourdieu (1984). For the school, though never explicitly stated, many of the choices which fed into the orchestra programme embrace ideas about valued forms of musical practice arguably derived from a dominant class perspective. Mr Samson explained 'we could do ukuleles, or guitars, or recorders but we don't because ... they're not so difficult as, kind of, that mastery of a skill that comes with a violin or viola or cello.' His words do not only speak to the objective, physical difficulty of playing those instruments; there is also a social prestige associated with the classical string family which these other instruments may lack. Arbitrary though Bourdieu 
demonstrates they are, such distinctions between instruments are manifestations of their perceived social and cultural worth.

\section{Compromising Tastes}

The music department's Orchestra Guiding Principles document explains how the music for the orchestra is chosen in an attempt to reconcile 'their' music with 'our' educational interests. The school clearly recognises the distance between their ideal repertoire, and the tastes of the majority of their students. By way of a compromise, the students regularly perform arrangements of modern pop songs. Much pop music is founded on similar melodic and harmonic foundations to classical music. As Miss Peters describes, 'pop music is repetitive, doesn't have very big leaps in pitch ... and it's very easy to separate into different parts ... and you can move that around the orchestra quite easily'. For many students, the inclusion of popular songs has made them feel more engaged with the initiative:

Jazmin: Yeah a lot of people didn't know what to play because they didn't know what was possible and then like some people recommended pop songs. And then the first time we ever played a pop song it sounded really, really good and, like, I was kind of shocked 'cause I never thought that you could play pop songs with an orchestra. So it's, like, I enjoyed it in that sense.

The school has achieved a form of reconciliation between the behaviours and aptitudes it ideally wishes to impart, and the prior cultural experiences and tastes of its students. They have identified an area of overlap in socially valued forms of practice from contrasting social fields: the ability to play a Classical instrument on the one hand, and the ability to play 'popular' music on the other. Furthermore, with each new year-group, the staff feel the challenge of overcoming students' prior reticence lessens. Miss Peters believes that 'now, after we've been doing it for four years, it's far more...normalised in the school.' However, in a clear reminder of the ultimate ambitions of the department, this greater normativity has led many to feel they 
could go further in incorporating classical pieces into the students' repertoire, as Mr Samson made clear:

Mr Samson: I think um ... we do our best to appeal to their tastes, and in doing that I think we sometimes don't address musical genres that we should in orchestra, and I think again it's the thing that will change ... I think from next year is when we'll start to branch out.

Interviewer: So do you mean more classical things?

Mr Samson: Yeah.

Mr Samson's comments betray the wider social expectation that one's repertoire should reflect the social, musical prestige of the instrument played. The temporary incorporation of pop music into the orchestra's repertoire may allay, but does not eradicate, the central tension of the programme: classical instrument playing, though chosen for its supposedly liberating potential, subtly demands the privileging of a particular set of dominant social practices. The implications of this fact are visible in the genres of music unintegrated into the orchestra.

Kareem, in Year 9, explained that 'when they started to introduce stuff that we listened to, it got better for us but still, like, some songs they don't play, like rap songs. Like, you can't play them on violin.' As Mr Samson made clear, 'lots of them listen to sort of quite extreme rap, kind of, artists. And, um ... to formalise those in a school environment I think is quite difficult.' Miss Peters is even blunter: 'I haven't yet found a way to get Krept and Konan or like...whatever...it's virtually impossible to write that for an orchestra to play. Um...and there's barely anything to study about it, musically, it's more about English.' Heavy rap music, on one level, is founded on a set of skills, such as linguistic flexibility and improvisation, which are simply not applicable to the playing of classical string instruments (although strings feature in sampling or 
production associated with hip-hop). On another level, these contrasting abilities carry differing levels of social value. The aim of the orchestra programme is to help set the students 'above' the supposed limitations of their upbringing, including tastes that do not translate to social mobility. Heavy rap simply fails to embrace a set of capacities which overlap sufficiently with the playing of a string instrument and its associated social value (and there are wider issues here involving the relationship of such music to 'Black' culture and its marginalisation in Western neoliberal educational discourse). It is clear, then, that even in attempting to provide an education framed explicitly in relation to social mobility, the school still privileges certain types of (dominant) cultural practice over those of its students.

\section{Materiality and Situated Learning}

\section{The Orchestra as a Community of Practice}

These tensions notwithstanding, students develop a degree of proficiency (that is, embodied capital) in their instruments through the years of compulsory instruction. Regardless of its wider social implications, we must still account for how such capital may be developed by those previously unexposed to it. To achieve this we draw now on Lave and Wenger's (1991) theory of Legitimate Peripheral Participation (LPP). Though the orchestra programme does not represent an organic 'community of practice', we argue it resembles such communities in many ways and, as such, pupils develop their instrument playing through gradual integration into a situated performance context.

We should first clarify exactly what we mean by 'the embodied capital of instrument playing'. As discussed by Gibson (2006), objects have affordances - ingrained expectations as to their appropriate use. Complicating this point, Brown et al. (1989) argue the proper use of an artefact can never be wholly inferred from its physical nature. As such it is an object's socially validated use, in combination with its physical form, which constitute its unique set of 
affordances. For instance, the 'correct' posture for playing the violin derives neither solely from the violin itself, nor the social conventions of violin playing, but rather an interaction of the two. The embodied capital of instrument playing, then, represents that set of practices which most effectively embraces the social and physical constraints of both the instrument and its contexts of use.

A new student at Regents Park is an initiate into a new community of musical practice. Though every child is given their string instrument upon arrival at school, they cannot take it home immediately. In their first two terms, they are introduced to their instrument, and then must pass a test and get parental agreement before they can do so. The responsibility of owning and caring for an instrument is only trusted to pupils after demonstration of the requisite physical capacities. In 'small groups' with Year 7 pupils it was common for a teacher to admonish a student for leaving their instrument on the floor or not paying sufficient attention to it. By emphasising and rewarding ownership at this early stage, the school is attempting to foster a tacit and instinctive care for the instruments, something captured by Sammy, a Year 8 , who claimed 'it's like having an animal; it gives you responsibility'.

By Year 8 , though the students may now be trusted with their instruments as valued possessions, the physical capacities that go with the instrument as producer of socially valued art-form are yet to develop. A violin, viola, or cello contains in its physical form many assumptions and intentions behind the correct sound it should produce. The absence of frets, for instance, prompts in the skilled player a fluid movement between notes, and rewards (through social validation) the development of glissando and vibrato. Before these things become instinctive, little stickers mark the position of notes on the necks of many instruments; notes are often described in terms of finger intervals rather than specific names; and teachers sometimes even physically adjust students' finger positions if they are producing notes out of 
tune. These all represent explicit attempts at the eventual internalisation of the 'correct' physical gestures for playing.

Year 8 also sees the introduction of students into a larger form of practice: whole-class rehearsals. Pupils are encouraged for the first time to consider their playing in relation to others. There is a materiality to the very structure of these rehearsals. Students are arranged by instrument, and the correspondence to a professional orchestra is no coincidence. It evokes physically the socially most legitimate forms of use for these instruments, and so establishes the connection between knowledge development and use. The material context of rehearsal and performance are one and the same.

A change in the learning process, which takes place with inclusion into a larger group, is made clear in this extract from a group of Year 9 violinists:

Kareem: I think in orchestra, it brings people together 'cause, like, we're playing the same thing. For example, if one of us makes a mistake in playing the tune, the other one corrects it so you have to follow what they're playing.

Yusuf: I think it becomes competitive, but it's competitive in like a ... there's no threat to the competitiveness ...

Interviewer: It's productive?

Yusuf: Yeah it's productive, like some people are more able to play better than others, so say for example he's more able to play, he could play a vibrato, but you can't and you try to challenge yourself to play it. And so it just it makes the orchestra all better.

With the introduction of form group and orchestra rehearsals, the parallels to a musical community of practice properly emerge. Pupils no longer learn from the direct instruction of the teacher but through awareness of others, recognition of their abilities and attempts at emulation (Kenny 2016). The teachers actively cultivate this environment, with explicit, didactic teaching declining, and deference to the students' abilities to identify their own faults 
and goals increasingly shown. The contrast between this format and other, more conventional, lessons is very clear:

Yusuf: I think you communicate more with your instruments in music, like, you do lots of work with the instruments. There's less talking. You try and challenge yourself to play stuff what you've not played before. The teacher might communicate to you using the instrument; if they want to play something you do call and response ... We've played lots of pieces, like probably ten this year, and each time, although we already know the piece, it gets trickier, with new dynamics, new ways of playing, new ways to put your fingers down ...

Tariq: On that point, like ... you say that we communicate through our instruments. There's also that, like, that although the rules are the same as in the classroom, it doesn't feel the same, because you're in control of something, and that thing is the noise that you're making through your instrument ...

Kareem: I think also when we're playing as an orchestra, and you have something difficult to do, you don't just shout and ask the teacher for help, you just look at what they're doing or you can look to your partner and see what he's playing and follow what he's playing.

The success of this situated model of teaching is seen in the contrasts between the Year 8 and Year 9 orchestras. Though rehearsals are similar, small differences between the students highlight what are in truth large discrepancies in ability. Year 8 pupils often checked their hands' placement on the fingerboard, while otherwise focussing intently on the sheet music. But among the Year 9s, few, if any, looked at their hands, postures were more relaxed, and several times players could be seen to smirk at their peers, pull faces or laugh at some private joke. Though this may seem less professional it belies a greater confidence and internalisation 
of the physical gestures of playing. As Jamal, a violinist in Year 9 explained, 'it's like something we could do with our eyes closed basically.'

There is not only greater effortlessness in their playing, but also greater uniformity. As discussed, the acceptable ways of playing emanate from a convergence of materially and socially-prompted norms, the stability of which are clearly seen than in the synchronicity of bows in an orchestra. In Year 8 there is much variation in bow movements, as some play multiple notes in a single sweep and others jerk back and forth for every note. By Year 9, the up-and-down of the bows occurs in synchronous waves, with the line between what is socially expected, and what feels personally instinctive, blurred by a year's absorption into the community of the orchestra. Almost all verbal instruction has disappeared; students are led by first and foremost by an embodied set of physical and cultural propensities.

The foregoing discussion makes apparent that the instrument programme is a complex social phenomenon. It provides students with a culturally valued skill to which they have had no prior exposure, and the efficacy with which this is achieved can perhaps be best explained through the situated learning environment facilitated by the orchestra. In this way, the students learn to play their instruments, certainly, but they also develop a number of distinct, and no less valuable, skills that characterise participation within a community of practice, including reflexivity, empathy and awareness of one's influence over the actions of others (and vice versa). Such qualities are reflected in the numerous student comments on comparing one's playing to others'; communicating through instruments; and the 'productive' atmosphere of orchestra rehearsals. In the moment of playing, the orchestra mediates the imposition of the socially valued, the systemically expected, and the culturally hegemonic; it provides, in the synchronous movement of bows, the swish and flick of the conductor's baton, the turning of a page, a momentary glimpse into the possibility of an education not subject to outside influence, but which exists within the communal practice of its constituent members. 


\section{Conclusions}

The effective development of novel, collective forms of knowledge derived from the embodied capital of instrument playing suggests the power of this kind of situated learning in revealing to participants how they learn together, and how this learning has value in offering moments for collective agency. However, in pursuing this end, the school still privileges certain forms of cultural participation which may serve to reproduce the assumptions linking these to social and educational success, rather than demonstrating the validity of the students' backgrounds, tastes and interests. In this way it may effect what Lave and McDermott $(2002,36)$ call the 'alienation of learning': the learning of instruments arguably serves primarily as a means to distinguish the pupils in the achievement of good grades, university places and future economic success. And come Year 9, or 11, or maybe 13 but certainly all too soon, these instruments will be taken back and reinvested in the next cohort. If there were ever an estrangement of learner from learning, it is such a removal of the very tool by which they achieved what they came to know. The ultimate removal of the instruments raises profound questions over whether the promises of future academic and vocational success repeatedly made by the school represent anything more than the 'cruel optimism' discussed by Berlant (2011).

This sobering thought leads us to reflect on the aims of Regent's Academy within the broader educational landscape of England today. Academies, in their various guises, now account for over $60 \%$ of all secondary schools in England. The success of academies, particularly as regards disadvantaged pupils, has been a source of much debate, with a report by the Sutton Trust $(2014,4)$ concluding that while 'on average, the improvement for disadvantaged pupils in $5 \mathrm{~A}^{*} \mathrm{CEM}_{1}$ in [academies] was greater than the average for all mainstream schools between 2011 and 2013', there was nonetheless 'enormous variation

\footnotetext{
${ }_{1}$ Five $A *-C$ grades at GCSE including English and Maths
} 
between chains, with only 16 out of 31' above average. Furthermore, in 2013, Ofsted concluded 'the proportion of outstanding schools in the least deprived areas is nearly double that found in the 'deprived' and 'most deprived' communities' (Wilshaw 2013, 21). Against this backdrop, the actions of schools like Regent's Academy take on a new significance. Freedom from the National Curriculum allows academies to specialise, or embrace novel teaching methods, and it seems inevitable that some, if not many, will be concerned with addressing socio-economic inequalities through such measures. But as the foregoing discussion makes clear, this aim can nonetheless coexist with the privileging of certain, dominant forms of cultural practice. And, indeed, as long as the popular discourse surrounding social mobility and cultural capital makes obscure this troubling paradox, there is little reason to suspect the situation will change. Though beyond the scope of this article, the questions that Regent's Academy ultimately raises are, firstly, whether upward social mobility is, regardless of one's background, only attainable through the emulation of dominant cultural logics of knowledge, taste, aspiration, and capital, and, secondly, if it does necessitate the suppression of alternative cultural practices, whether social mobility as currently formulated is the inherently desirable end point that it is so often presented to be. 


\section{References}

Berlant, L., 2011. Cruel Optimism. Durham, NC: Duke University Press.

Bourdieu, P., 1977a. Cultural Reproduction and Social Reproduction. In J. Karabel \& A. H. Halsey, eds. Power and Ideology in Education. Oxford: Oxford University Press.

Bourdieu, P., 1984. Distinction: A social critique of the judgement of taste, London: Routledge.

Bourdieu, P., 1977b. Outline of a Theory of Practice, Cambridge: Cambridge University Press.

Bourdieu, P., 1970. The Berber house or the world reversed. Social science information, 9(2), pp.151-170.

Bourdieu, P., 1986. The forms of capital. In J. Richardson, ed. Handbook of Theory and Research for the Sociology of Education. New York: Greenwood, pp. 46-58.

Bourdieu, P., 1990. The logic of practice, Stanford, California: Stanford Univeristy Press.

Bourdieu, P., 1996. The state nobility: Elite schools in the field of power, Stanford, California: Stanford Univeristy Press.

Bourdieu, P. \& Passeron, J., 1977. Reproduction in education, culture and society, London: Sage.

Brown, J.S., Duguid, P. \& Collins, A., 1989. Situated Cognition the Culture of Learning. Educational Researcher, 18(1), pp.32-42.

Ericsson, C., 2002. Från guidad visning till shopping och förströdd tillägnelse: moderniserade villkor för ungdomars musikaliska lärande., Malmö: Lund Univeristy.

Folkestad, G., 2006. Formal and informal learning situations or practices vs formal and informal ways of learning. British Journal of Music Education, 23(02), p.135. 
Gibson, W., 2006. Material culture and embodied action: Sociological notes on the examination of musical instruments in jazz improvisation. Sociological Review, 54, pp.171-187.

Goldthorpe, J.H., 2007. “Cultural Capital”: Some Critical Observations. Sociologica, 1(2), pp.1-23.

Goodman, A. Gregg, P., Chowdry, H., Crawford, C., Dearden, L., Joyce, R., Sibieta, L., Sylva, K. \& Washbrook, E., 2010. Poorer children's educational attainment: how important are attitudes and behaviour?, Joseph Rowntree Foundation. Available online at: http://www.jrf.org.uk/system/files/poorer-children-education-full.pdf [4 March 2015]

Green, L., 2005. The Music Curriculum as Lived Experience: Children's "Natural” MusicLearning Processes. Music Educators Journal, 91(4), pp.27-32.

Halstead, J.M., 1994. Muslim Attitudes to Music in Schools. British Journal of Music Education, 11(02), pp.143-156.

Latour, B., 1999. Pandora's hope: essays on the reality of science studies, Cambridge, MA: Harvard University Press.

Latour, B., 2005. Reassembling the social-an introduction to actor-network-theory, Oxford: Oxford University Press.

Latour, B., 1987. Science in action: How to follow scientists and engineers through society, Milton Keynes: Open University Press.

Lave, J., 1982. A Comparative Approach to Educational Forms and Learning Processes. Anthropology \& Education Quarterly, 13, pp.181-187.

Lave, J., 1996. Teaching, as Learning, in Practice. Mind, Culture, and Activity, 3, pp.149164.

Lave, J. \& McDermott, R., 2002. Estranged labor learning. Outlines: Critical Social Studies, 4, pp.19-48. 
Lave, J. \& Wenger, E., 1991. Situated learning: Legitimate peripheral participation, Cambridge: Cambridge University Press.

Miller, D., 1987. Material culture and mass consumption, Oxford: Basil Blackwell.

Miller, D., 2005.Introduction. In D. Miller, ed. Materiality, Durham NC: Duke University Press.

Moore, R., 2004. Cultural capital: objective probability and the cultural arbitrary. British Journal of Sociology of Education, 25(4), pp.445-456.

Prior, N., 2013. Bourdieu and the Sociology of Music Consumption: A Critical Assessment of Recent Developments. Sociology Compass, 7(3), pp.181-193.

Scherger, S. \& Savage, M., 2010. Cultural transmission, educational attainment and social mobility. The Sociological Review, 58(3), pp.406-428.

Shilling, C., 2004. Physical capital and situated action: a new direction for corporeal sociology. British Journal of Sociology of Education, 25(4), pp.473-487.

Valenzuela, R. \& Codina, N., 2014. Habitus and flow in primary school musical practice: relations between family musical cultural capital, optimal experience and music participation. Music Education Research, 16(4), pp.505-520.

Wilshaw, M., 2013. Unseen children - access and achievement 20 years on, Ofsted. Available online at: https://www.gov.uk/government/publications/unseen-childrenaccess-and-achievement-20-years-on [12 March 2015]

Zipin, L., S. Sellar, M. Brennan, and T. Gale. 2015. Educating for Futures in Marginalized Regions: A Sociological Framework for Rethinking and Researching Aspirations. Educational Philosophy and Theory: Incorporating ACCESS 47(3): 227-46. doi:10.1080/00131857.2013.839376. 